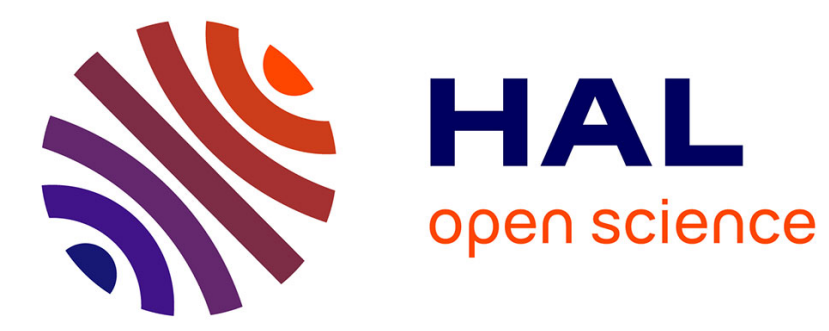

\title{
ITER Robots: Introducing School Students to Robotics and Project Management
}

Jean-Pierre Martins, Julien Hillairet, Sylvie André-Mitsialis, Rosa Aspilcueta, Marie Alfonsi, Alain Barbuti, Alexandre Berne, Jean-Michel Bottereau, Vincent Bruno, Jean-Baptiste Civet, et al.

\section{To cite this version:}

Jean-Pierre Martins, Julien Hillairet, Sylvie André-Mitsialis, Rosa Aspilcueta, Marie Alfonsi, et al.. ITER Robots: Introducing School Students to Robotics and Project Management. Physics Education, 2020, 10.1088/1361-6552/ab5ce1 . cea-02455442

\section{HAL Id: cea-02455442 https://hal-cea.archives-ouvertes.fr/cea-02455442}

Submitted on 26 Jan 2020

HAL is a multi-disciplinary open access archive for the deposit and dissemination of scientific research documents, whether they are published or not. The documents may come from teaching and research institutions in France or abroad, or from public or private research centers.
L'archive ouverte pluridisciplinaire HAL, est destinée au dépôt et à la diffusion de documents scientifiques de niveau recherche, publiés ou non, émanant des établissements d'enseignement et de recherche français ou étrangers, des laboratoires publics ou privés. 


\title{
ITER Robots: Introducing School Students to Robotics and Project Management
}

\author{
Jean-Pierre Martins ${ }^{1}$, Julien Hillairet ${ }^{2}$, Sylvie André-Mitsialis ${ }^{3}$, Rosa Aspilcueta ${ }^{1}$, \\ Marie Alfonsi ${ }^{3}$, Alain Barbuti ${ }^{2}$, Alexandre Berne ${ }^{2}$, Jean-Michel Bottereau ${ }^{3}$, Vincent \\ Bruno $^{2}$, Jean-Baptiste Civet ${ }^{5}$, Laban Coblentz ${ }^{1}$, Jennifer Colombet ${ }^{3}$, Hans \\ Decamps ${ }^{1}$, Fabien Ferlay ${ }^{2}$, Jean-Pierre Friconneau ${ }^{2}$, Delphine Keller ${ }^{2}$, Olivier \\ Lagay $^{5}$, Véronique Marfaing ${ }^{3}$, Lorena Martinez ${ }^{3}$, Christian Merveille ${ }^{3}$, Bruno \\ Pélissier ${ }^{5}$, Rolland Rajaonarivony ${ }^{5}$, Xavier Regal-Mezin ${ }^{2}$, Christophe Roux ${ }^{2}$, Sophie \\ Soufflet-Jacquis ${ }^{4}$, Shira Tabachnikoff ${ }^{1}$, Benoit Vincent ${ }^{2}$, Sébastien Vives ${ }^{2}$ \\ ${ }^{1}$ ITER Organization, Route de Vinon-sur-Verdon, CS 90 046, 13067 St Paul Lez Durance, France \\ ${ }^{2}$ CEA, IRFM, F-13108 St-Paul-Lez-Durance, France \\ ${ }^{3}$ Agence ITER France, Cadarache 13108 St Paul lez Durance, France \\ ${ }^{4}$ Voix OFF for Agence ITER France, Cadarache 13108 St Paul lez Durance, France \\ ${ }^{5}$ Minister of French National Education \\ E-mail: Jean-Pierre.Martins@iter.org ; julien.hillairet@cea.fr; sylvie.andre@cea.fr
}

\begin{abstract}
Originally developed by ITER, CEA, Agence ITER France and the French Ministry of Education, the ITER Robots Contest is an engineering robotics based competition open to high school and primary students across the South of France. The challenge is to build a reduced scale robot to simulate a maintenance situation inside the future ITER Tokamak machine, namely the remote handling of components in a hostile environment. The ITER Robots Contest has grown in popularity, with more than 600 participants in the 2019 edition. As part of their technical and science curriculum, students work in teams, for over 6 months, to acquire technical skills and knowledge on robotics and fusion energy, solve problems, develop communication skills, and run their projects. This contest corresponds to the highschool educational "cross disciplinary approach", from technology to French, foreign languages, as well as history from science to general international knowledge. The contest day, each team`s robot undertakes a number of tasks evaluated by jury composed of ITER and CEA engineers. Teams are also evaluated on communication skills and fusion energy knowledge.
\end{abstract}

Keywords: Nuclear Fusion, ITER, Remote Handling, robotics, education, communication, school, STEM

\section{Introduction}

Deep inside all stars in the universe, light elements such as Hydrogen atoms join together to form larger atoms such as Helium. This process, called nuclear fusion, generates heat energy, which leads stars like our Sun to shine and radiate their energy to our planet. For the fusion to occur, positively charged protons must have sufficient energy to overcome the Coulomb force, which naturally repel them. In terms of temperatures, the matter must be heated to the order of tens of millions of degrees, where it behaves in a plasma state. Research aiming to develop controlled nuclear fusion for a 
civil purpose such as electricity generation began since the 1940s. However, the task is not easy: generating and above all maintaining plasmas at these temperature levels present many difficulties. Despite the constant progress achieved during years, so far scientists have not created more energy that they have used to heat the plasma. As the performances increase partly with the plasma volume, the size of the experimental machines had increased with each new generation. This increase in dimensions led countries to work more and more toward international experiments and the field of nuclear fusion research is nowadays very open to internal collaborations. ITER $^{1}$ is the biggest international experimental project under construction in the south of France, which purpose is to demonstrate the physical and technological feasibility of producing power from nuclear fusion [1]. The project is funded and run by seven members: the European Union, India, Japan, China, Russia, South Korea and the United States.

ITER will be the world largest nuclear fusion experiment. The plasma will be confined in an 840 cubic meter chamber pumped to very high vacuum levels, using superconducting magnets up to 13.5 teslas. As the heated plasma will produce large neutron radiation into the components facing it, human access during shutdown periods will be prohibited. Maintenance by robots (Remote Handling) of various elements of the machine is thus mandatory [2][3]. In the ITER scenario during maintenance phases, each robot has to follow a dedicated path to transfer components from the tokamak and to the repair area, named hot cell building.

\section{Cross-disciplinary approach}

The ITER Robots competition is organised for school children located in Provence-Alpes-Côte d'Azur in order to introduce the various challenges ITER is facing. This contest aims to bring technical challenges to students into a crossdisciplinary approach [4]. The number of participants in the ITER Robots competition, created by the Agence ITER France $^{2}$ in 2012, is growing. From the original two regional schools that subscribed to the first tournament, it has grown to incorporate 600 participants from 30 regional education establishments. The competition consists firstly in creating and programming a robot and secondly in participating to a final contest with the automated-robot.

ITER Robots involves the ITER France Agency, the AixMarseille-Nice academy (Minister of French National Education), ITER Organization and CEA/IRFM (Commisariat à l'Énergie Atomique / "Institut de Recherche sur la Fusion par confinement Magnétique”). As an

\footnotetext{
${ }^{1}$ http://www.iter.org

2 http://www.itercadarache.org
}

extension of the scientific educational workshops organized throughout the year during schools visits to the CEA and ITER research laboratories, the objectives of the competition are multi-disciplinary: scientific, technical, cultural, economic and social. Each team is asked to create a robot that will be able to achieve ITER-like challenges reproducing the main remote handling equipment operations of the future facility.

The robots' architecture was initially based on LEGO bricks with sensors controlled by a LEGO MINDSTORMS $®$ programmable unit (Figure 1). When considering kids and school capabilites, others technologies have been introduced such as Arduino® (or equivalent) boards and 3D printed elements (Figure 2). Each robot is named by its creators. The purpose of the contest is to challenge team composed of full classes or few students from primary schools (aged from 10 to 11), middle schools ("collège", aged from 11 to 15) and high schools ("lycée", aged from 16 to 18) to remote handling problematics. Junior high school team of students can be held within their established technological school programmes (in 7th, 8th and 9th grades or within interdisciplinary educational programme projects). Secondary school students can integrate the competition to their first and final year of high school technological programmes (in science, engineering or technology). In 2019, ITER Robots becomes part of the regular syllabus for primary school students as a technology lesson.

Scaled-down and adapted challenges involving totally autonomous robots illustrate the real-life problems ITER will be facing. Like the ITER scientists, students are actively involved for a period of 4 to 6 months in project management, such as project analysis, planning and testing. Students must combine the theoretical concepts learned at school and apply lessons during robots design, programming and testing activities.

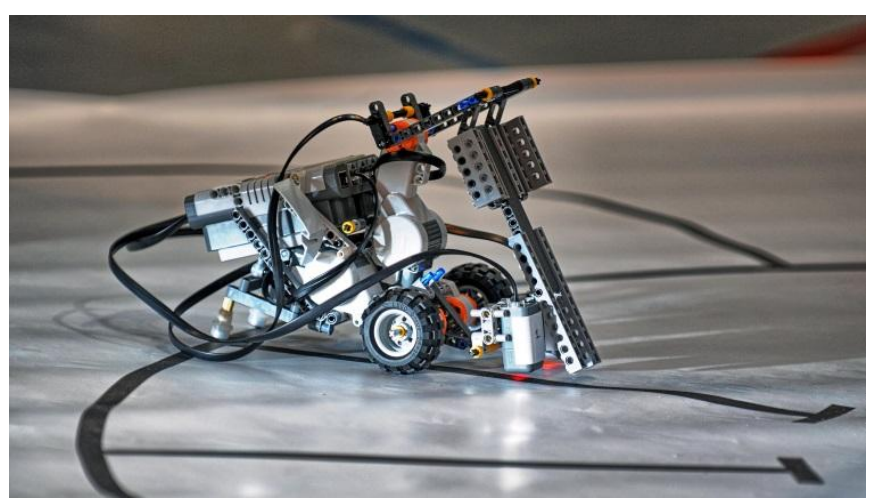

Figure 1. Picture of a robot LEGO MINDSTORMS ${ }^{\circledR}$ based during the TRANSPORT challenge. (@C.Roux, CEA) 

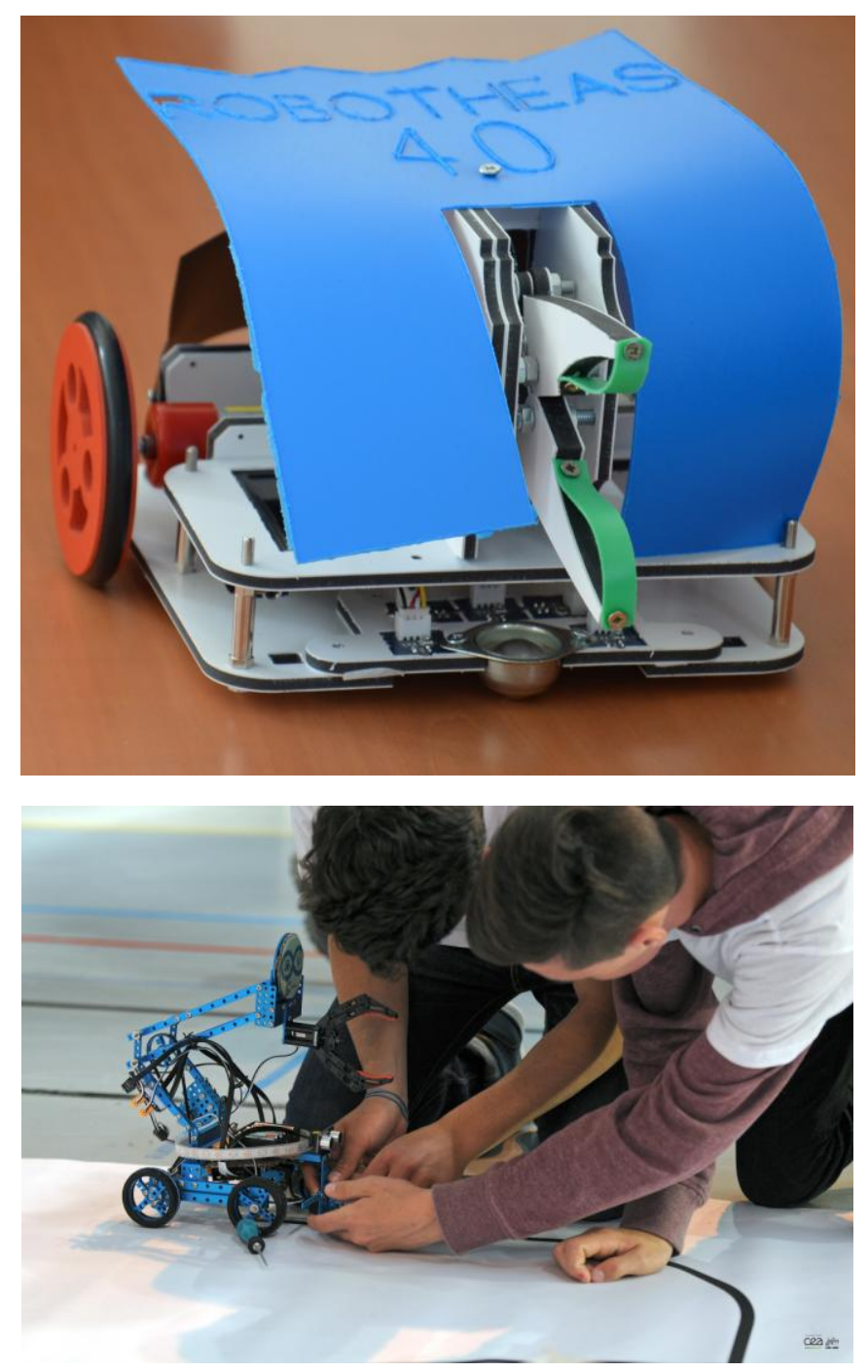

Figure 2. Pictures of a custom made robot and a 'from the shelf' plateform during the TRANSPORT challenge. (CC.Roux, CEA)

Technical issues are not the only challenges that ITER scientists must face. Working in a multicultural environment, with worldwide working cultures and lifestyles is also an important aspect of the programme. Thus, in addition to the robotics challenge, the competition includes a broad general knowledge preparation about the ITER project itself and its seven members (culture, geography, history, economy, etc.). Humanities teachers from nearby middle schools are involved in the competition and teams are evaluated through a quiz during the day of the finals. Also, to enforce the communication side, teams shall prepare a dedicated booth and magazine illustrating their work along the year. A dedicated jury evaluates the work the day of the contest.

The challenge terms and conditions are introduced to the schools during a specific event organized in December/January (Figure 3). This is also the opportunity to explain the ITER project in general and to illustrate ITER staff daily work, by means of questions/answers.

\begin{tabular}{|c|c|c|c|c|c|c|c|c|c|}
\hline \multicolumn{3}{|l|}{$\sqrt{7}$} & \multicolumn{2}{|l|}{5} & \multicolumn{2}{|l|}{$b$} & \multicolumn{3}{|c|}{5} \\
\hline Sep & Oct & Nov & Dec & Jan & Feb & Mar & Apr & May & Jun \\
\hline \multicolumn{10}{|c|}{ School year period } \\
\hline
\end{tabular}

Figure 3. Typical schedule of the ITER Robots competition.

In order to help the school teams during their activities, a follow-up is organized a few months before the final in a project review format, led by ITER, Agence ITER France and CEA and schools teachers. Teams are asked to present the status of their works, organisation, associated schedule and remaining issues. These reviews are thus the opportunity to identify and help eventual teams experiencing troubles, in order to limit the disappointing experiences of coming to the final with a non-operational robot. The challenge final gathers all the participants (close to 600 in 2019, representing 30 schools) in a local gymnasium for a full day of competition (Figure 4).

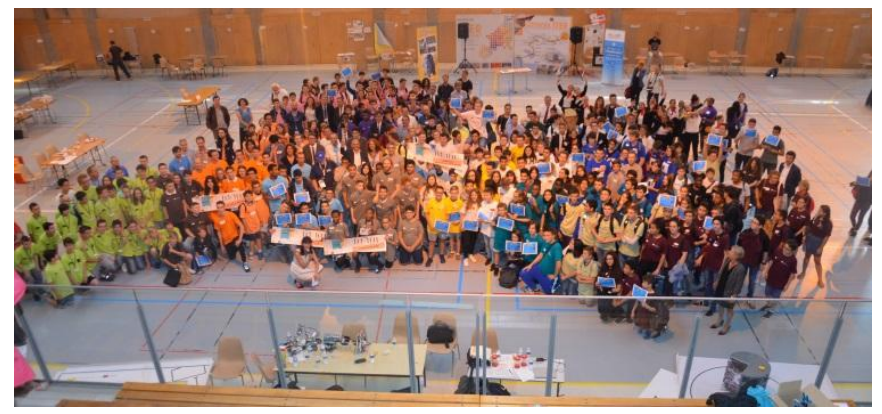

Figure 4. ITER Robots Challenge 2018 Final: close to 600 students, representing 48 teams from 24 schools participated in the event organized by the Agence ITER France in "Lycée Des Iscles" in Manosque. 30 schools have participated in 2019. (๔) Agence Iter France)

\section{Robotics challenges}

The purpose of the contest is for teams of students to design and build robot(s) which will be evaluated during the final stage of the competition. The challenges are downscaled replications of real remote handling tasks that will occur in the future facility. Indeed, when the nuclear phase of the experiment will begin, some areas of the tokamak become man access restricted. Inspections or repair of any of the tokamak components (weighing up to 50 tonnes) in the 
restricted areas will thus require reliable and robust remote handling techniques.

In brief, the overall maintenance strategy of the tokamak consists on transporting the large components from their locations in the reactor to the repair workshops (called hot cells) for technical operations (cleaning, replacement of components, etc.), see Figure 5.

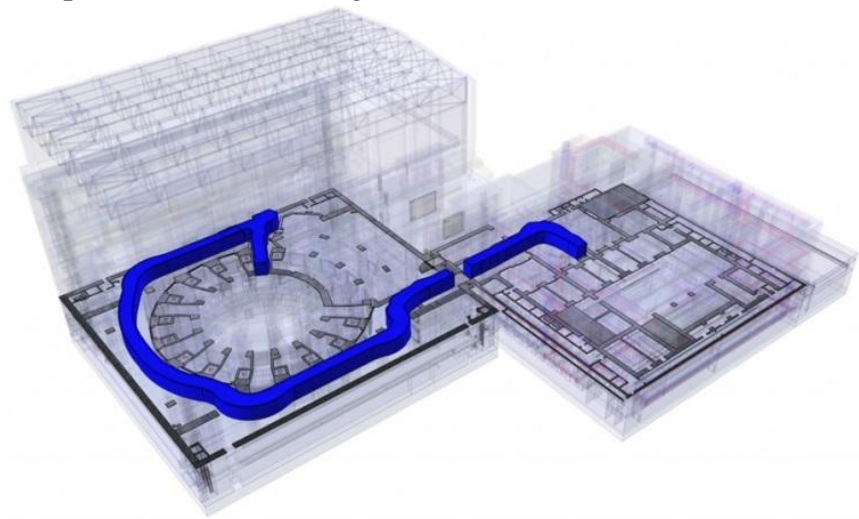

Figure 5. Due to the limited space in the nuclear environment of ITER, transport cask trajectories are complex. In blue: sample trajectory between a port in Tokamak Building (left) and the hot cell facility (right). (@iter.org)

Therefore the main steps of the strategy have been converted into 4 complementary tests:

- WAYS: this test is mimicking the tasks that will have to be operated in an autonomous way by mobile vehicles following predefined guiding lines. These robots, called "casks", are mobile containers, the size of a truck.

- TRANSPORT: the 'casks' function is to transport components from inside the vacuum chamber of the ITER Tokamak to the maintenance workshop. This test is reproducing this operation but instead of transporting $45 \mathrm{t}$ port plugs, the robot will handle a small colored wooden piece from inside a Tokamak simplified mock-up to a box representing the hot cells (Figure 6).

- PICK AND PLACE: once the components from the tokamak will be transferred inside the hot cells, they will be handled to be transported onto specific working areas. The test is imitating that part of the process.

- COOPERATE: As a synthesis, Cooperate combines the 3 other tests into a single long sequence where the wooden blocks shall be transported from their location into the Tokamak mock-up to their maintenance specific area in hot cells. The name comes from the fact that at least 2 different robots shall be used and operate together to perform the task.

The WAYS challenge is a speed race on several circuits, illustrated in the Figure 6. Robots must follow autonomously black lines printed on the floor. Speed and lines follow-up performances are evaluated. Teams competing for this challenge must choose two circuits to evaluate their robots on. Circuits with difficulties such than intersections and nodes yield more points than simpler ones. The robot that conquers the circuit the fastest and in the most precise way makes it team a winner.
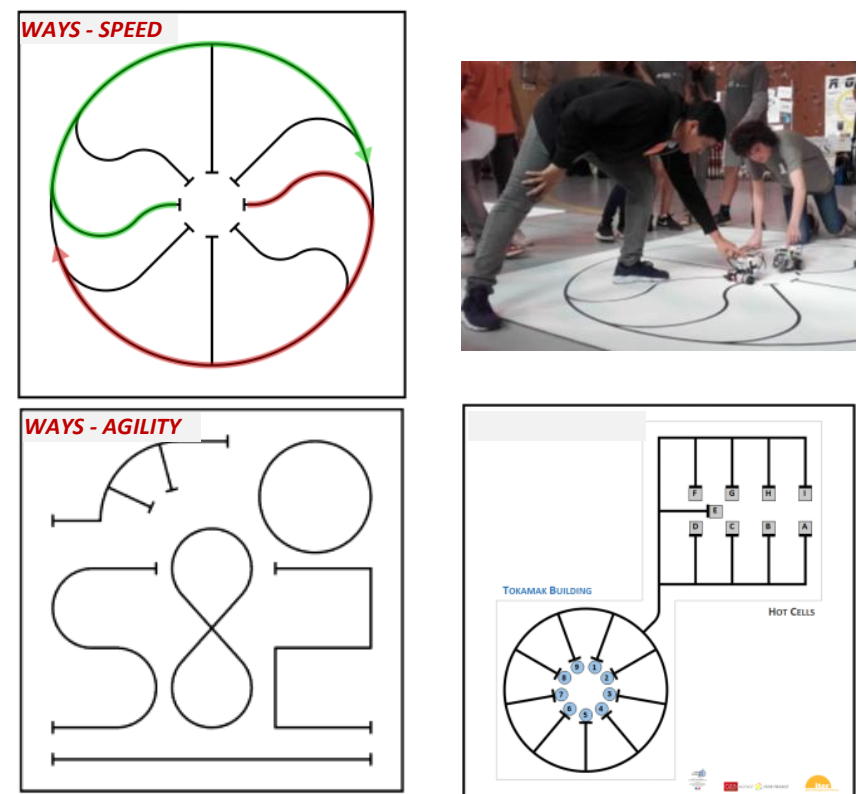

Figure 6. Illustration of the various circuits proposed for the WAYS challenge.

The TRANSPORT challenge combines a mobility test including a back and forth rides on the circuit and a remote handling test to pick and drop-off several blocks (representing components) in the deposit zone (representing the hot-cell). The aim is to transport the maximum number of blocks (up to 5 blocks) in a minimum time (to reduce the length of the maintenance phase).
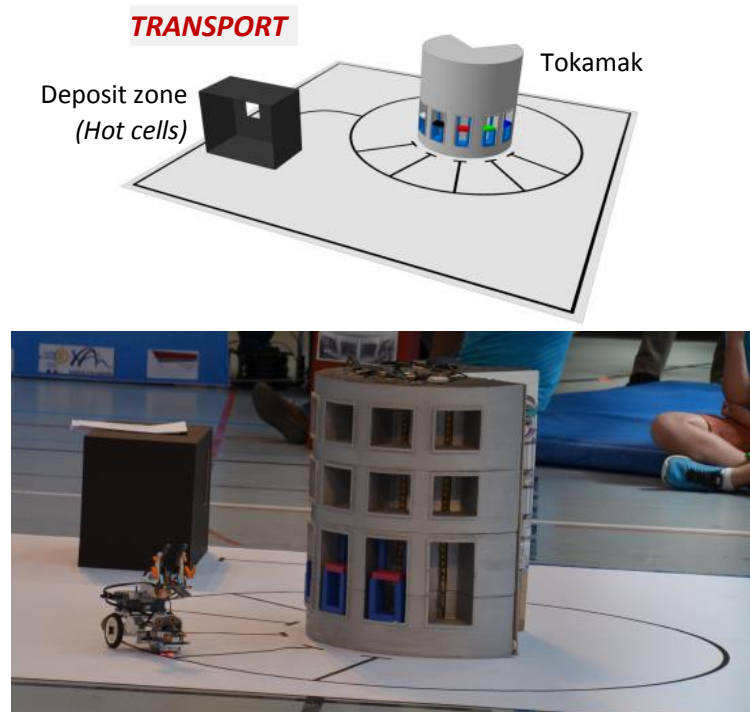

Figure 7. Picture of the TRANSPORT challenge. The robot must autonomously follow the tracks plotted on the floor and pick a brick (here in red) in each "port" of the ITER mock-up (in the middle). Once got, the robot must bring back the brick to the "hot-cell" (black zone at the left of the figure). 
The PICK AND PLACE challenge includes pick and place operations from point $\mathrm{A}$ to point $\mathrm{B}$ (on a dedicated area representing the hot-cell) using colour recognition sensors in order to place the blocks on the corresponding colour zones (Figure 8).
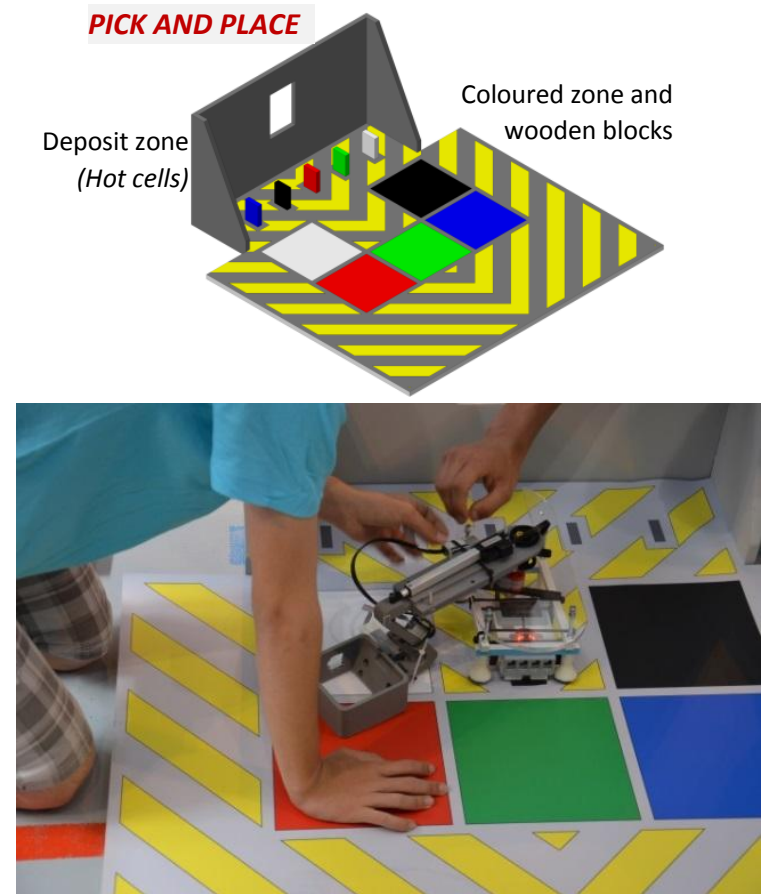

Figure 8. Picture of a robot during the PICK AND PLACE challenge. The robot has to autonomously pick five coloured bricks (initially disposed in a random order at the top of the area) and place them to their respective colour zones. (ङ Agence Iter France)

The CO-OPERATE challenge combines Transport and Pick and place challenges. Two robots must work in cooperation, to pick and drop-off the several blocks and to place the maximum number of blocks on their corresponding colour zones (Figure 9).

\section{CO-OPERATE}

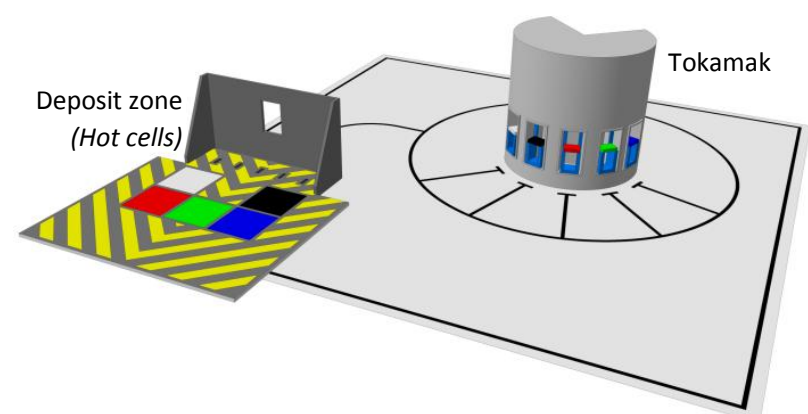

Figure 9. Illustration of the CO-OPERATE configuration combining TRANSPORT and PICK AND PLACE.

\section{Student Reception and Lessons Learned}

ITER Robots is an adventure shared by up to 600 students, teachers and engineers each year since 2012. These eight years of the ITER Robots allow us to draw several lessons learned.

Robotics provides a fun and exciting environment for school students and is an ideal subject to get them interested to science, technology, engineering, and math (STEM). ITER is a unique mega-project, which is currently challenging all present technological domains (cryogenics, superconducting, vacuum, high temperature plasma, etc.). Combined together, ITER Robots is a challenge introducing collegiality, experimentation and project management to the students in order to solve a real problem, mimicking an important aspect of ITER. During the challenge, students can benefit from a scientific environment by being in contact with scientists, engineers and technicians. This opportunity has proved to encourage some of them to be interested in engineering or science careers. This is particularly important, especially from students coming from disadvantaged areas, as they never envisaged it possible to work on such fields. This is also important to limit young people's disaffection for scientific and technical careers. In Europe, studies have determined that registrations in physics classes had dropped dramatically [5].

Teachers enjoy the practical approach developed with the ITER Robots competition. This contest corresponds to the current educational "cross disciplinary approach", from technology to French, foreign languages as well as history, from science to general international knowledge. Reaching the goals of the project requires groups to work in a team, which is becoming more and more a common practice in the French educational system. Learning to work in a group, sharing the work according to each team member's wishes and abilities, is a relevant experience for the rest of their scholarship and future career. Disappointments are also part of the adventure and the intermediate project reviews are a good opportunity to boost students and to give them precious tips. Small details, such as not to forget to bring new batteries for the robots for the day of the final, may have big consequences.

\section{Conclusion}

Originally developed by Agence ITER France (CEA), ITER and the French Ministry of Education, the ITER Robots Contest is an engineering robotics based competition open to high school and primary students across the South of France. The challenge is to build a small robot to simulate a maintenance situation inside the future ITER Tokamak 
machine, namely the remote handling of components in a hostile environment.

Now in its 8th year, the ITER Robots Contest has grown in popularity, with more than 600 participants in the 2019 edition. As part of their technical and science curriculum, students work in teams, for over 6 months, to acquire technical skills and knowledge on fusion energy, solve problems, develop communication skills, and run their projects. On the day of the contest each team's robot undertakes a number of tasks which are evaluated by a jury composed of ITER and CEA engineers. The teams are also evaluated on their communication skills and knowledge of fusion energy. The winning teams are rewarded with a series of prizes.

In brief, ITER Robots is the oportunity for students to discover one of the world's largest big science project, participate in a playful robotic contest and learn about carrying a project. Currently only deployed in the South of France around the ITER site, the contest could further be developed through the ITER project domestic agencies in the involved countries.

\section{Acknowledgements}

The authors would like to thank the lycée Les Iscles from Manosque, le lycée Leau from Marseille, the lycée Saint Martin Bret from Manosque and the lycée Brochier from Marseille for their help in organizing the event.

\section{Disclaimer}

The views and opinions expressed herein do not necessarily reflect those of the ITER Organization.

\section{References}

[1] B. Bigot, Comptes Rendus Phys. 18, 367 (2017).

[2] ITER - Maintain and upgrade: ITER's Remote Handling https://www.youtube.com/watch?v=xfJQJI8jEnA

[3] AIA: Articulated Inspection Arm - In-vessel inspection robot for operated tokamak assesment http://irfm.cea.fr/Phocea/Video/index.php?id=62

[4] ITER Robots 2018 teaser video https://www.youtube.com/watch?v=z6rhHYrs980

[5] F. S. Becker, Eur. J. Eng. Educ. 35, 349 (2010). 